\title{
Numerical simulation of water flow in a large waste rock pile, Haizhou coal mine, China
}

\author{
Hadi Hajizadeh Namaghi ${ }^{1} \cdot$ Sheng Li $^{1} \cdot$ Liguo Jiang $^{2}$
}

Received: 3 December 2014/ Accepted: 13 May 2015/Published online: 23 May 2015

(C) Springer International Publishing Switzerland 2015

\begin{abstract}
Waste rock is the large volume of broken rock and low grade ore materials tend to create potential problems, such as acid mine drainage (AMD), leaching of heavy metals, and slope stability problems. These problems are related to the flow of water through the waste rock. In this study, long term numerical simulations of unsaturated flow in a large waste rock pile are conducted to investigate the effect of internal variability in water flow and saturation. The approach first consists of a basic geotechnical properties investigation to define the main features of the pile. This is followed by numerical simulations of the unsaturated flow through the pile based on the results from the field and laboratory characterization. The simulation results showed that pile is unable to fully saturate and drain during the simulated period. It was also found that high evaporation and the high bottom flux rate and also coarse grain nature of waste rock materials results holding few amounts of water in the system.
\end{abstract}

Keywords Waste rock pile - Stochastic properties · Unsaturated water flow $\cdot$ Bottom flux $\cdot$ Storage

\section{Introduction}

Waste rock is the large volume of broken rock, excavated in order to gain access to the ore deposit, and low grade ore materials that cannot be processed commercially. Waste

Hadi Hajizadeh Namaghi

hadi.hajizadeh@gmail.com

1 College of Mining, Liaoning Technical University, Fuxin, China

2 School of Mechanics and Engineering, Liaoning Technical University, Fuxin, China rock is commonly deposited in large piles that are typically 10 to $30 \mathrm{~m}$ high, but range up to $150 \mathrm{~m}$ in height, and up to several square kilometers in area (Blowes 1997). In coal mining, waste rocks are referred to as "spoils" (Lottermoser 2007). Some waste rock piles tend to create potential problems, such as acid mine drainage (AMD), leaching of heavy metals, and slope stability concerns. These problems are related to the flow of water through the waste rock (Dawood et al. 2011).

Waste rocks are generally employed in waste piles dry and they tend to progressively increase in water content with time through infiltration and fluid flow (Williams and Rohde 2008). Potential drainage inputs include the infiltration of snow melt and rainfall through the surface and along the batters, as well as additions of runoff and groundwater along the edge and bottom of the dump (Price 2009). Waste rock by its nature is highly heterogeneous with particle size varying from boulders of several meters to clay size particles (Noel and Ritchie 1999; Smith et al. 1995). This heterogeneity means that multiple flow mechanisms characterize the movement of water within the piles (Fala et al. 2005). The grain size distribution and the method of construction of the dumps in the waste rock play controlling roles in the movement of fluids (water and gas) inside a pile (Fala et al. 2003). The lithological properties of the ore deposit and its overburden, the mining method, and the construction techniques for the pile largely determine these two factors (Smith and Beckie 2003).

The exposure of minerals in mine waste materials to atmospheric oxygen leads to the weathering of primary minerals, and the formation of secondary minerals and dissolved weathering products. The most common reaction is the oxidation of metal sulfides to produce dissolved sulfate, acidity and free metal ions. Water infiltrating the surface of a waste rock pile carries these weathering 
products to the environment. So understanding water transport is also an important aspect in the management of the environmental impact caused by these dumps (Nichol 2002; Noel and Ritchie 1999).

Waste rocks are unsaturated environments and therefore waste rock management requires addressing all the complex flow conditions inherent to unsaturated zone hydrology (O'Kane 2000). Unsaturated flow in coarse, heterogeneous waste rock exists in the form of matrix flow through the finer-grained fraction of the waste rock, and preferential flow through the coarser-grained fraction (Wagner et al. 2006). Numerical modeling techniques can lead to a better quantitative understanding of the physical and geochemical processes leading to the production of AMD in sulfidic wastes (Franklin et al. 2008) and are quite useful to obtain a better understanding of the factors that affect the response of a waste rock pile (Dawood and Aubertin 2009). The majority of simulations deal with simple internal waste rock pile structures and homogeneous materials. However, difficulty in characterizing the inherent heterogeneity of waste rock pile has limited advances in understanding its importance on physical processes (Lahmira et al. 2007). The main objective of this paper is to assess hydraulic behaviors with several different internal configurations in a large waste rock pile.

\section{Waste rock properties}

The Haizhou opencast coal mine is located at Fuxin, Liaoning province in northeast of China. The main waste pile at this mine extend to a height of $170 \mathrm{~m}$ with slope angles of $46^{\circ}$ and are heterogeneous and stratified. In order to characterize physical and hydrological properties of Haizhou waste pile, the pile was divided into 8 zones (WR1 to WR8, from top to toe). The percentage of coarse rocks (i.e. cobbles and boulders) covering surface of rock

Table 1 Summary of basic characteristics of waste rock samples

\begin{tabular}{lccrl}
\hline Property & Minimum & Maximum & Mean & $\begin{array}{l}\text { Standard } \\
\text { deviation }\end{array}$ \\
\hline $\mathrm{D}_{10}(\mathrm{~mm})$ & 0.1 & 0.4 & 0.3 & 0.1 \\
$\mathrm{D}_{60}(\mathrm{~mm})$ & 2.3 & 7.3 & 4.9 & 1.6 \\
Porosity & 0.4 & 0.5 & 0.4 & 0.1 \\
$\begin{array}{l}\text { Specific gravity Gs, } \\
\quad\left(\mathrm{g} / \mathrm{cm}^{3}\right)\end{array}$ & 2.1 & 2.8 & 2.5 & 0.2 \\
Liquid limit & 0.4 & 0.5 & 0.4 & 0.1 \\
Plastic limit & 17.9 & 28.7 & 23.9 & 3.9 \\
Plasticity index & 5.4 & 24.7 & 12.1 & 6.4 \\
Hydraulic & 1.3 & 8.5 & 4.3 & 2.9 \\
$\quad$ conductivity $(\mathrm{m} /$ & & & & \\
$\quad \mathrm{s}) \times 10^{-6}$ & & & & \\
\hline
\end{tabular}

pile was used to separate different zones. Similar to other waste dumps, the coarse rocks increased from top to toe. A field program was conducted on the top and slope surfaces of the dump. The strategy was taking so many samples from each zone and mixing them to have a composite sample representative of each zone.

The tests completed on the geotechnical and hydrological properties of the samples presented in Table 1.

\section{Model characteristics}

The conceptual model of studied waste rock pile is based on the west side of the pile and has a width of $150 \mathrm{~m}$ and a height of $100 \mathrm{~m}$ (Fig. 1). Field observation and laboratory experiments of sample suggest that 4 different materials (L1-L4) with minor hydraulic properties can be identified.

The numerical simulations of the Haizhou rock pile were implemented using the HYDRUS-2D variably saturated flow model (Simunek et al. 2006). The HYDRUS-2D model uses the Richards equation as the governing equation to describe Darcy-type fluid flow in a variably saturated porous media. HYDRUS-2D solves the governing equations numerically using Galerkin-type linear finite element schemes. In this study, van Genuchten equations (van Genuchten 1980) is used to describe the data. This expression permits a relatively good description of $\theta(\mathrm{h})$ for many soils using only a limited number of parameters. The Van Genuchten soil moisture retention characteristic is defined as:

$\theta(h)=\theta_{r}+\frac{\theta_{s}-\theta_{r}}{\left(1+|\alpha h|^{n}\right)^{m}}$

where, $\mathrm{h}$ is the soil water suction (pressure) head (L), $\theta(\mathrm{h})$ is the volumetric water content in dependency of the suction head $\mathrm{h}\left[\mathrm{L}^{3} \mathrm{~L}^{-3}\right], \theta_{\mathrm{r}}$ is the residual water content

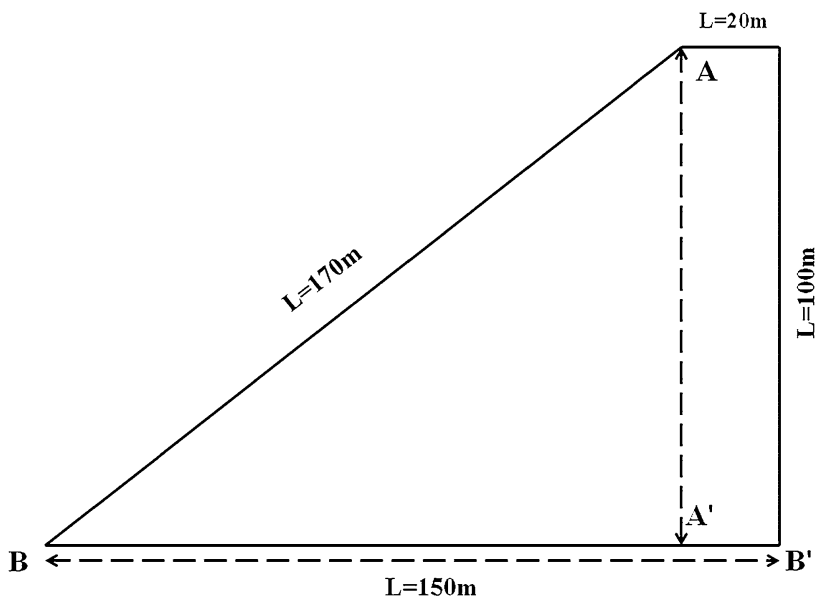

Fig. 1 Geometrical configuration of the simulated waste rock pile 
$\left[\mathrm{L}^{3} \mathrm{~L}^{-3}\right], \theta_{\mathrm{s}}$ is the saturated water content $\left[\mathrm{L}^{3} \mathrm{~L}^{-3}\right], \alpha\left[\mathrm{L}^{-1}\right]$ is a fitting parameter that is inversely proportional to the air-entry pressure value, $\mathrm{n}[-]$ is a parameter related to the width of pore-size distribution of the media and $\mathrm{m}$ is a constant that can be approximated by $\mathrm{m}=1-1 / \mathrm{n}$ (van Genuchten, 1980).

Similarly as for the water retention curve, analytical models are often used also for the hydraulic conductivity function. The Mualem (1976) model describes the hydraulic conductivity as a function of volumetric water content. Combining the van Genuchten (1980) retention function (Eq. 1) with the Mualem model gives:

$K(h)=K_{s} \cdot S_{e}^{l}\left[1-\left(1-S_{e}^{1 / m}\right)^{m}\right]^{2}$

$S_{e}=\frac{\theta-\theta_{r}}{\theta_{s}-\theta_{r}}$

where $\mathrm{K}_{\mathrm{s}}$ represents the saturated hydraulic conductivity, $\mathrm{S}_{\mathrm{e}}$ is an effective degree saturation, $\mathrm{K}(\mathrm{h})$ is the hydraulic conductivity at a certain suction head $\mathrm{h}, \mathrm{l}$ is the poreconnectivity parameter which was estimated by Mualem (1976) to be about 0.5 as an average for many soils.

The water retention curve; WRC, (or soil water characteristic curve, SWCC) of the waste rock samples was estimated by the Modified Kovacs (MK) model (Aubertin et al. 1998, 2003). The properties required to obtain the WRC using this model are the grain size curve of the material $\left(\mathrm{D}_{10}\right.$ and $\left.\mathrm{D}_{60}\right)$ and the void ratio (e).

The MK model can be described by a set of equations:

$$
\begin{aligned}
& S_{r}=\frac{\theta}{n}=S_{c}+S_{a}^{*}\left(1-S_{c}\right) \\
& S_{a}^{*}=1-\left\langle 1-S_{a}\right\rangle \\
& S_{c}=1-\left[\left(h_{c o} / \Psi\right)^{2}+1\right]^{m} \exp \left[-m\left(h_{c o} / \Psi\right)^{2}\right] \\
& S_{a}=a_{c} C_{\Psi} \frac{\left(h_{c o} / \Psi_{n}\right)^{2 / 3}}{e^{1 / 3}\left(\Psi / \Psi_{n}\right)^{1 / 6}} \\
& C_{\Psi}=1-\frac{\operatorname{Ln}\left(1+\Psi / \Psi_{r}\right)}{\operatorname{Ln}\left(1+\Psi_{0} / \Psi_{r}\right)} \\
& h_{c o}=\frac{0.75 * \cos \beta_{d}}{e D_{10} * 1.17 * \log \left(C_{u}\right)+1} \\
& \Psi_{r}=0.86 h_{c o}^{1.2}
\end{aligned}
$$

where $\theta$ is the volumetric water content, $\mathrm{n}$ is the total porosity, $S_{c}$ and $S_{a}$ correspond to capillary and adhesive components of $\theta . D_{10}$ is the diameter $(\mathrm{cm})$ corresponding to $10 \%$ passing on the cumulative grain-size distribution, $\beta_{\mathrm{d}}$ corresponds to the contact angle taken as zero (for drying conditions), $\mathrm{C}_{\mathrm{U}}$ is the coefficient of uniformity $\left(\mathrm{C}_{\mathrm{U}}=\mathrm{D}_{60} /\right.$ $\mathrm{D}_{10}$ ), and $\mathrm{e}$ is the void ratio (From porosity can be calculated by: $e=n /(1-n))$. $m(-)$ is a pore size coefficient an often be closely approximated by $m=1 / C_{U} \cdot a_{c}(-)$ is the adhesion coefficient, $\psi_{\mathrm{r}}$ is the suction at residual water content $(\mathrm{cm})$, and $\psi_{\mathrm{n}}$ is a normalizing parameter for unit consistency $\left(\psi_{\mathrm{n}}=1 \mathrm{~cm}\right.$ when $\psi$ and $\mathrm{h}_{\mathrm{co}}$ are given in $\left.\mathrm{cm}\right)$. $\mathrm{C}_{\psi}$ is a correction factor for full dryness and $\psi_{0}$ is the suction at complete dryness $\left(\psi_{0}=10^{7} \mathrm{~cm}\right)$. The adhesion coefficient $a_{c}$ is approximately constant $\left(a_{c}=0.01\right.$, when suctions are in $\mathrm{cm}$ ).

The matric suctions were then plotted against their corresponding estimated water contents to yield the WRC. The predicted curves from MK model for the waste rock samples were then fitted with the van Genuchten (1980) equation (Eq. 1) using the RETC code (van Genuchten et al. 1991) to determine best fitted van Genuchten parameters and hydraulic conductivity $\mathrm{k}$ functions (Table 2). The unsaturated hydraulic conductivity curves were predicted using the Mualem (1976); van Genuchten (1980) model (Eqs. 2, 3). The corresponding water retention curves and unsaturated hydraulic conductivity curves are shown in Figs. 2 and 3, respectively.

The initial condition of the simulation domain was given in form of the soil water pressure head. The water table was fixed at $-5 \mathrm{~m}$ relative to the base of the rock pile and pressure head was assumed to be uniform from the base to the top of the pile. The upper boundary of the conceptual model represented the surface of the rock pile, which was exposed to atmospheric conditions. Therefore, for the purposes of this study, a seasonally-varying recharge is assigned. Because of symmetry, an impervious boundary condition imposed on the right hand side of the pile corresponds to a vertical line of separation for the flow net inside the pile. No-flux boundary conditions are specified for impermeable boundaries where the flux is zero perpendicular to the boundary. The lower boundary along the bottom of the bedrock was treated as a free drainage boundary to allow water to leave the flow domain under non-forced drainage conditions. The condition is a reasonable boundary condition at the bottom of a flow domain for situation where the water table is located far below the domain of interest (McCord et al. 1991). A pressure head of $-5 \mathrm{~m}$ (50 $\mathrm{kPa}$ suction) equivalent to have a water

Table 2 The van Genuchten model parameters for defined layers of waste rock materials used in numerical study

\begin{tabular}{lllll}
\hline $\begin{array}{l}\text { Layer/ } \\
\text { Parameter }\end{array}$ & L1 & L2 & L3 & L4 \\
\hline$\theta_{\mathrm{r}}$ & 0.018 & 0.017 & 0.008 & 0.011 \\
$\theta_{\mathrm{s}}$ & 0.43 & 0.39 & 0.51 & 0.40 \\
$\alpha_{\mathrm{v}}\left(\mathrm{cm}^{-1}\right)$ & 0.123 & 0.167 & 0.44 & 0.28 \\
$\mathrm{n}_{\mathrm{v}}$ & 3.3 & 3.2 & 3.4 & 3.3 \\
$\mathrm{~K}_{\mathrm{s}}(\mathrm{m} / \mathrm{s})$ & $1.75 \times 10^{-6}$ & $2.58 \times 10^{-6}$ & $3.9 \times 10^{-6}$ & $8.44 \times 10^{-6}$ \\
\hline
\end{tabular}




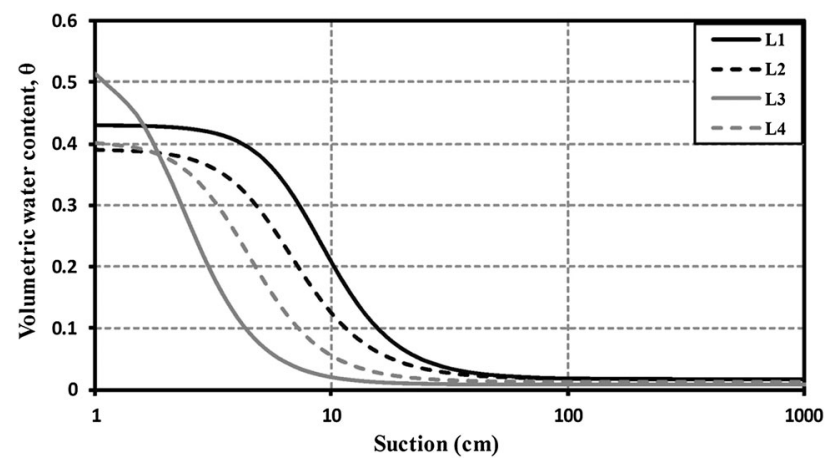

Fig. 2 Water retention curves of the waste rock materials predicted with the MK mode

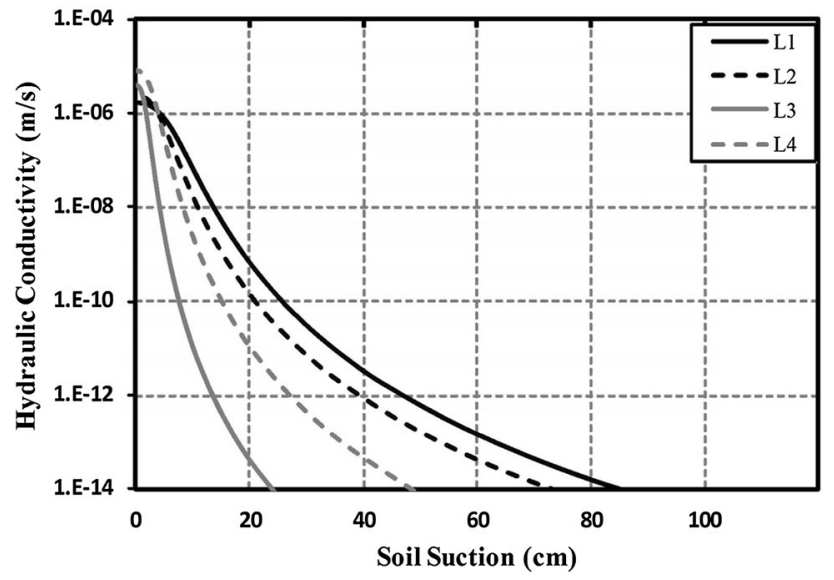

Fig. 3 Unsaturated hydraulic conductivity curves $\left(K_{\text {unsat }}\right)$ of the waste rock materials

table $5 \mathrm{~m}$ below the bottom of pile was used. This condition mimics the effect of a coarse, well-drained layer typically found at the base of a waste rock pile (Fala et al. 2005).

\section{Simulation of unsaturated flow}

Two different sets of scenarios with spatially variable soil hydraulic properties were considered:

1. Layered pile (S1).

2. Layered pile with stochastic properties (S2, S3, S4).

The reason for utilizing the different types of simulations was to show the sensitivity of each method with respect to hydraulic variations of the system. All simulations were made for periods of 10 years. Running the model for multiple years will minimize the influence of the boundary conditions and allow the moisture content to be more naturally distributed throughout the system (Hudson et al. 2012). There is no any drainage in the pile and it is not anticipated to happen in coming years. Williams (2011) estimated that for a typical dump height of $30 \mathrm{~m}$ and a typical mine life of 20 years, during which the waste pile is left uncovered, a semi-arid to arid climate would cause drainage in about 25 years.

\section{Base case}

The base case simulations (S1) (Fig. 4) assume a layered waste rock pile with minor hydraulic variations. The 4 general layers (L1-L4) were defined from sampling zones which their hydraulic parameters were shown in Table 2. Having more realistic distribution of hydraulic parameters, stochastic methods were used in scenarios 2 to 4 for studied waste rock pile.

The upper part of the pile shows a volumetric water content corresponding to the applied atmospheric conditions while lower parts show a water content that corresponds to the surface conditions applied during the previous periods. These conditions have created a pseudostationary condition (Fala et al. 2005, 2013). The simulation S1 (Fig. 4) represents the effects of layering in distributions water content in a large waste rock pile. The study of observation lines (Fig. 4) suggest that there are some abrupt changes in water content in vertically and horizontally direction. Although these variations have sharply happened but maximum water content reach to less than 0.2. The volumetric moisture content distribution within this model is in the range of 0.01 to 0.08 . These moisture contents equate to less than $20 \%$ of saturation within the waste rock material. The variation rates is higher in vertical profile $\left(\mathrm{AA}^{\prime}\right)$ compared to horizontal profile $\left(\mathrm{BB}^{\prime}\right)$ which latter shows slight increase in water content from left to right at base.

\section{Simulation with stochastic properties}

Waste rock piles typically heterogeneous, even within a given characteristic zone. Therefore, to accurately simulate flow and transport in rock piles, models must include the variability in soil hydraulic properties. The influence of spatial variability of hydrogeological properties can be assessed by using a stochastic approach (Fala et al. 2005, 2013). In this case, it is assumed that the value of a given property at two locations depends on the distance between them; the closer they are, the closer their property values will be (on average).

HYDRUS-2D generates a 2D-field of scaling factors related to the hydraulic conductivity function, using factors applied to hydraulic conductivity $(\alpha \mathrm{K})$, suction (or pressure, $\alpha$ h) and volumetric water content $(\alpha \theta)$. The code assumes that the hydraulic variability in a given area can be approximated by means of a set of scaling transformations which relate the individual soil hydraulic characteristics 
Fig. 4 Water content contours of layered waste rock pile (Simulation S1) and variations of water content in two observation lines $\mathrm{AA}^{\prime}$ and $\mathrm{BB}^{\prime}$
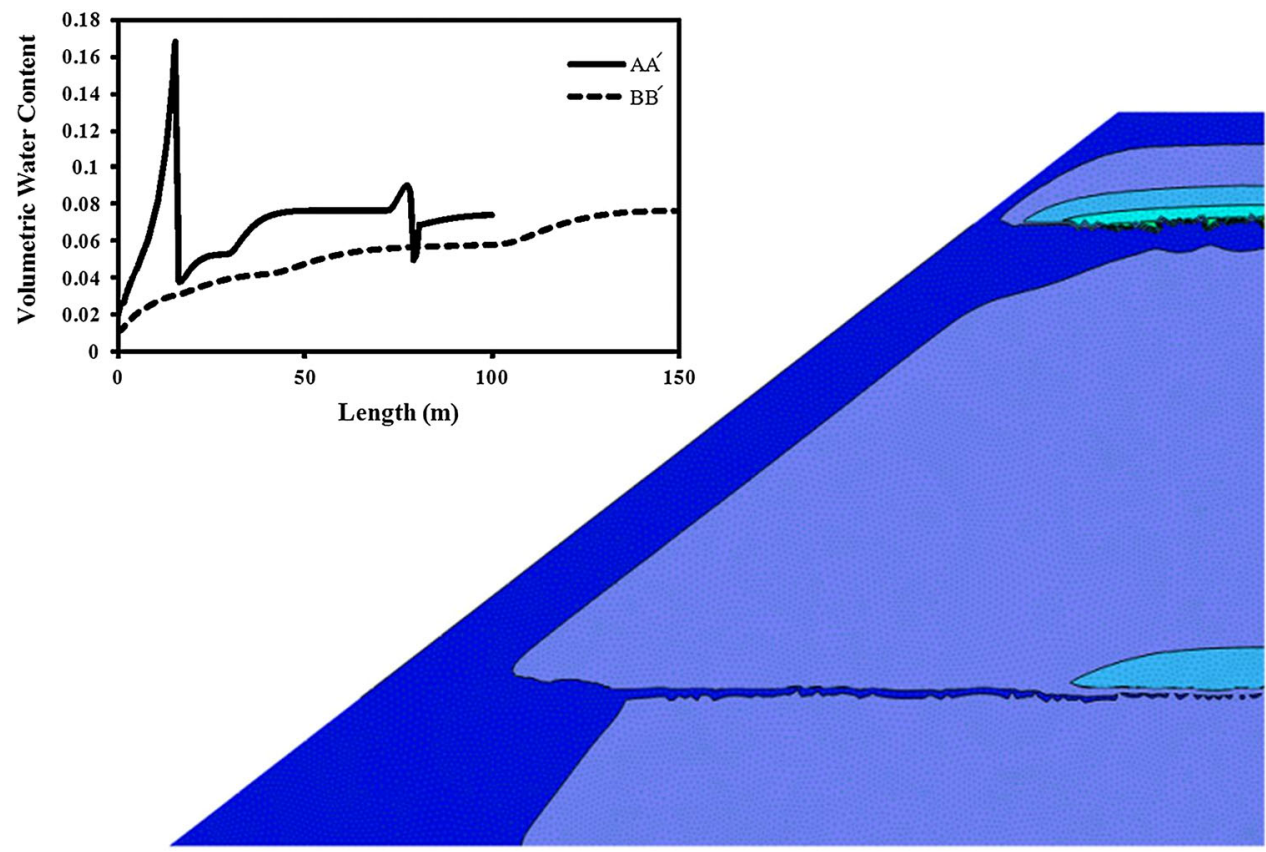

$\begin{array}{llllllllllll}0.009 & 0.047 & 0.084 & 0.122 & 0.159 & 0.197 & 0.234 & 0.272 & 0.309 & 0.347 & 0.384 & 0.422\end{array}$

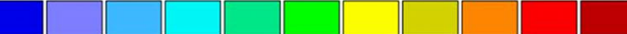

$\theta(\mathrm{h})$ and $\mathrm{K}(\mathrm{h})$ to reference characteristics $\theta^{*}(\mathrm{~h} *)$ and $\mathrm{K}^{*}\left(\mathrm{~h}^{*}\right)$. The technique is based on the similar media concept introduced by Miller and Miller (1956) for porous media which differ only in the scale of their internal geometry. Three independent scaling factors are embodied in HYDRUS:

$$
\begin{aligned}
& K(h)=\alpha_{k} K^{*}\left(h^{*}\right) \\
& \theta(h)=\theta_{r}+\alpha_{\theta}\left[\theta^{*}\left(h^{*}\right)-\theta_{r}^{*}\right] \\
& h=\alpha_{h} h^{*}
\end{aligned}
$$

in which, for the most general case, $\alpha \theta$, $\alpha \mathrm{h}$ and $\alpha \mathrm{K}$ are mutually independent scaling factors for the water content, the pressure head and the hydraulic conductivity, respectively. A detailed discussion of the scaling relationships and their application to the hydraulic properties of a heterogeneous waste rock piles is given by Fala et al. (2008, 2013).

The soil heterogeneity in the simulations is included by treating $\mathrm{K}_{\mathrm{s}}$ as the realization of a spatially randomly distributed field with a specified standard deviation and correlation length. The method of Miller and Miller (1956) is used with a logarithmic standard deviation of the hydraulic conductivity $\left(\log \sigma_{\mathrm{k}}\right.$ ) equal to 0.3 ; the other properties ( $\alpha \mathrm{h}$ and $\alpha \theta$ ) are considered homogeneous (constant) for each domain. The values of the correlation length are also required (i.e. spatial distribution of the hydrogeological characteristics) and vary from 2 to $50 \mathrm{~m}$. The choice of correlation length and its direction depends on the spatial distribution of the hydrogeological properties, which are related to the grain size distribution of samples taken in the field (Fala et al. 2008; Dawood et al. 2011). The corresponding fields are illustrated in Fig. 5, which shows horizontal, vertical and mixed correlations for studied waste rock pile. Multiple field tests showed that scaling factors of both matric potential and hydraulic conductivity usually follow a lognormal distribution (Hopmans 1987; Tuli et al. 2001) and this scaling approach successfully predicted the heterogeneity of soil hydraulic properties of the soil samples collected at their field sites (Tuli et al. 2001). The statistical parameters for simulation S2, S3 and $\mathrm{S} 4$ are given in Table 3.

In simulation $\mathrm{S} 2$ (Fig. 6), stochastic properties with horizontal preferences $\left(\sigma_{\mathrm{k}}=0.3\right.$, CorX $=50$, CorZ $\left.=2\right)$ were applied for a layered waste rock pile. The results were similar for layered waste rock without stochastic properties (S1). Similar to S1, there is some variation in upper part for water content and the variation can be seen with less variation in lower part. The vertical variation $(0.1-0.17)$ in water content is higher compared to horizontal one $\left(\mathrm{BB}^{\prime}\right)$ at the base (Fig. 6).

The simulation S3 (Fig. 7) is related to a layered waste rock pile with vertical correlation. The water distribution is similar to S2 with some minor difference in center of pile. In line $\mathrm{AA}^{\prime}$ the volumetric water content reached its highest value $(0.16)$ at about $15 \mathrm{~m}$ from top and the decrease sharply (Fig. 7). Then, water content increase to toe. In observation line $\mathrm{BB}^{\prime}$, volumetric water contents gently increase from left to right (0.01-0.1). Regarding applying different water flow parameters for different layers, they are all less than $20 \%$ of waste rock saturation. 


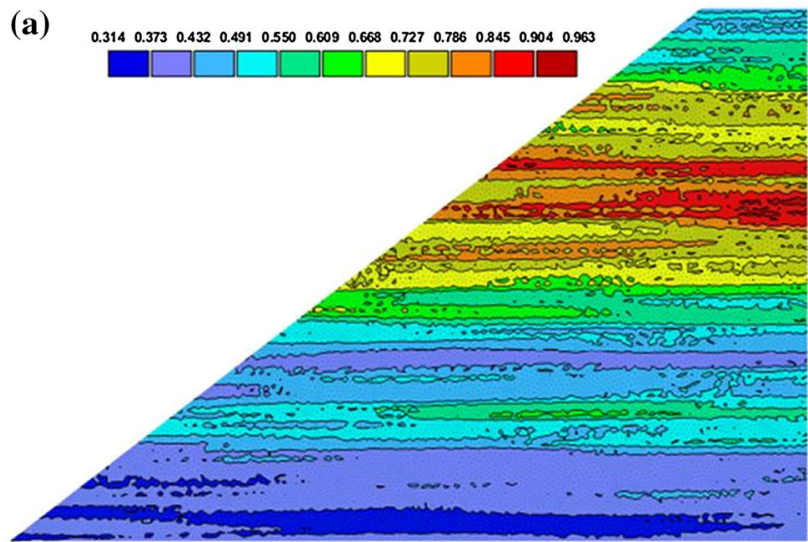

(b)

(c)

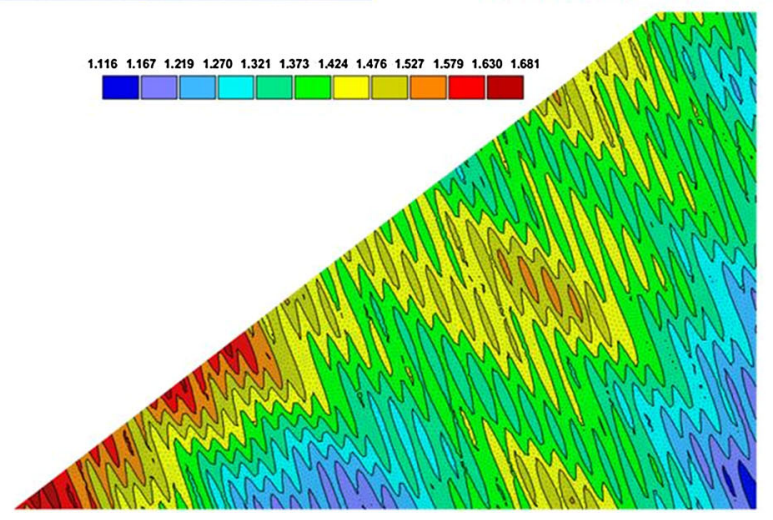

Fig. 5 Scaling factors related to hydraulic conductivity: a horizontal correlation, b vertical correlation, $\mathbf{c}$ mixed correlation

In simulation S4 (Fig. 8) a mixed correlation length for a layered waste rock piles with stochastic parameters: $\sigma_{\mathrm{k}}=0.3$ and Cor- $\mathrm{X}$ and Cor- $\mathrm{Z}$ equals to $50 \mathrm{~m}$. The flow patterns are similar to $\mathrm{S} 2$ and $\mathrm{S} 3$ except that, water content near to residual water content is predominant at the base of the pile. Similar to $\mathrm{S} 3$ there is a abrupt increase in water content in $15 \mathrm{~m}$ from the top (0.16) followed by sharp decrease in water content (Fig. 8). However, all water contents are less than $20 \%$ of waste rock saturation.

\section{Water balance}

The infiltration is defined as the water that enters the waste rock pile by downward flow through the surface materials. The seepage is the outflow of water along the

Table 3 Applied scaling factors in stochastic simulations

\begin{tabular}{llccc}
\hline Simulation ID & Correlation Type & $\sigma_{\mathrm{k}}$ & $\mathrm{K}$ & \\
\cline { 3 - 5 } & & & Corr-X & Corr-Z \\
\hline S2 & Horizontal & 0.3 & 50 & 2 \\
S3 & Vertical & 0.3 & 2 & 50 \\
S4 & Mix & 0.3 & 50 & 50 \\
\hline
\end{tabular}

base of the pile. A water balance can be defined as the mass of water moving through the components of the hydrologic cycle (Tetra Tech 2012). The surface of the rock pile is the part of the model where climate and soil come in contact and water moves according to the unsaturated soil physics rules through the waste rock material. Some parts of this water evaporated and remaining infiltrate into the soil. At the end, water reaches the bottom of the model which is a free draining discharge point. Storage is the water that is considered temporarily static in the system, such as pore water or groundwater (Tetra Tech 2012). The cumulative storage was computed for the waste rock pile system using Hydrus-2D for all simulations. Storage was calculated using a water balance approach as shown in Eq. 14.

$S=Q A-Q E-Q B$

where, $\mathrm{S}=$ storage, $\mathrm{QA}=$ surface flux (at the atmospheric boundary), $\mathrm{QE}=$ evaporation flux and $\mathrm{QB}=$ bottom flux. Actually, the atmospheric condition comprises the infiltration component of system while, bottom flux (free drainage) is seepage component.

The all simulations were based on fixed atmospheric condition and difference was just applied in method of distribution of hydraulic parameters (stochastic methods) 
Fig. 6 Water content contours of layered waste rock pile with horizontal correlation

(Simulation S2) and variations of water content in two observation lines $\mathrm{AA}^{\prime}$ and $\mathrm{BB}^{\prime}$

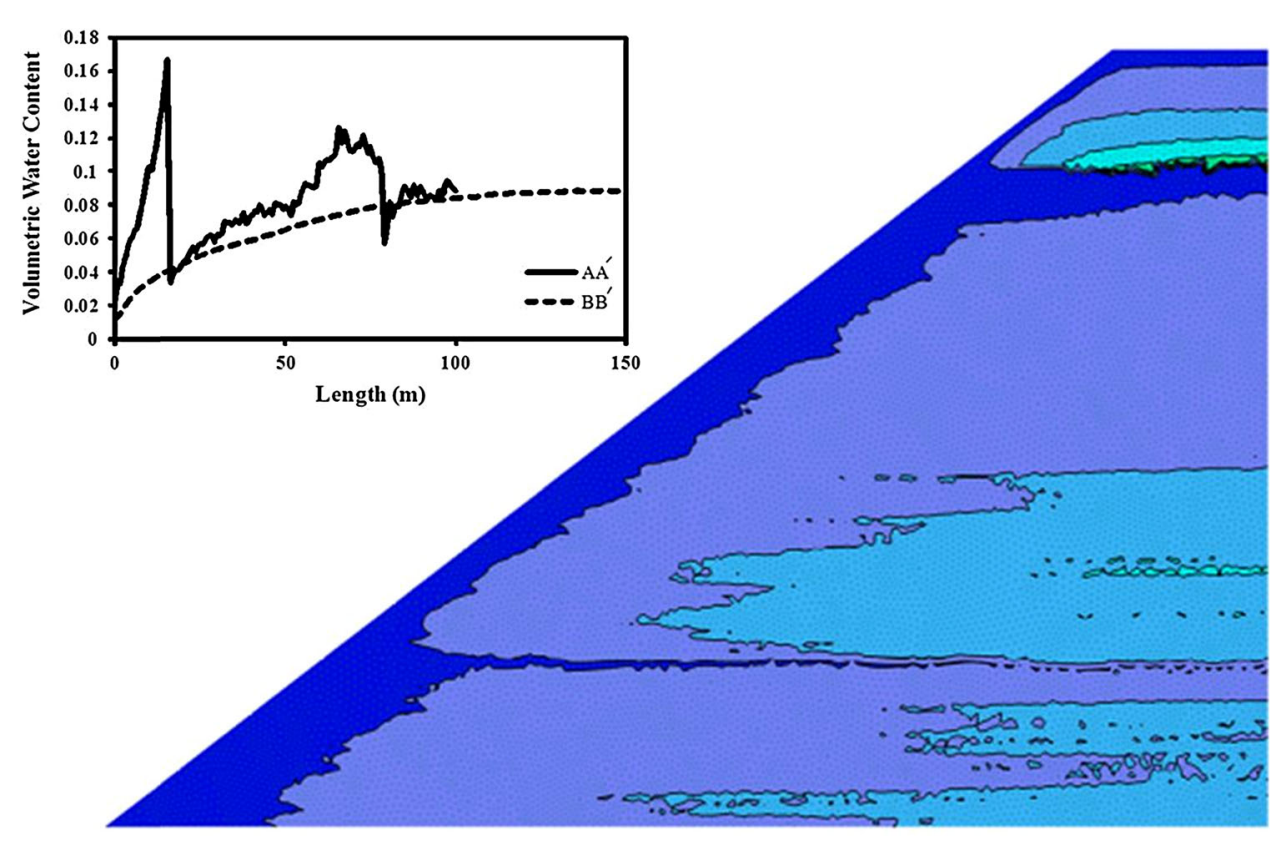

$\begin{array}{llllllllllll}0.009 & 0.047 & 0.085 & 0.123 & 0.160 & 0.198 & 0.236 & 0.274 & 0.312 & 0.349 & 0.387 & 0.425\end{array}$
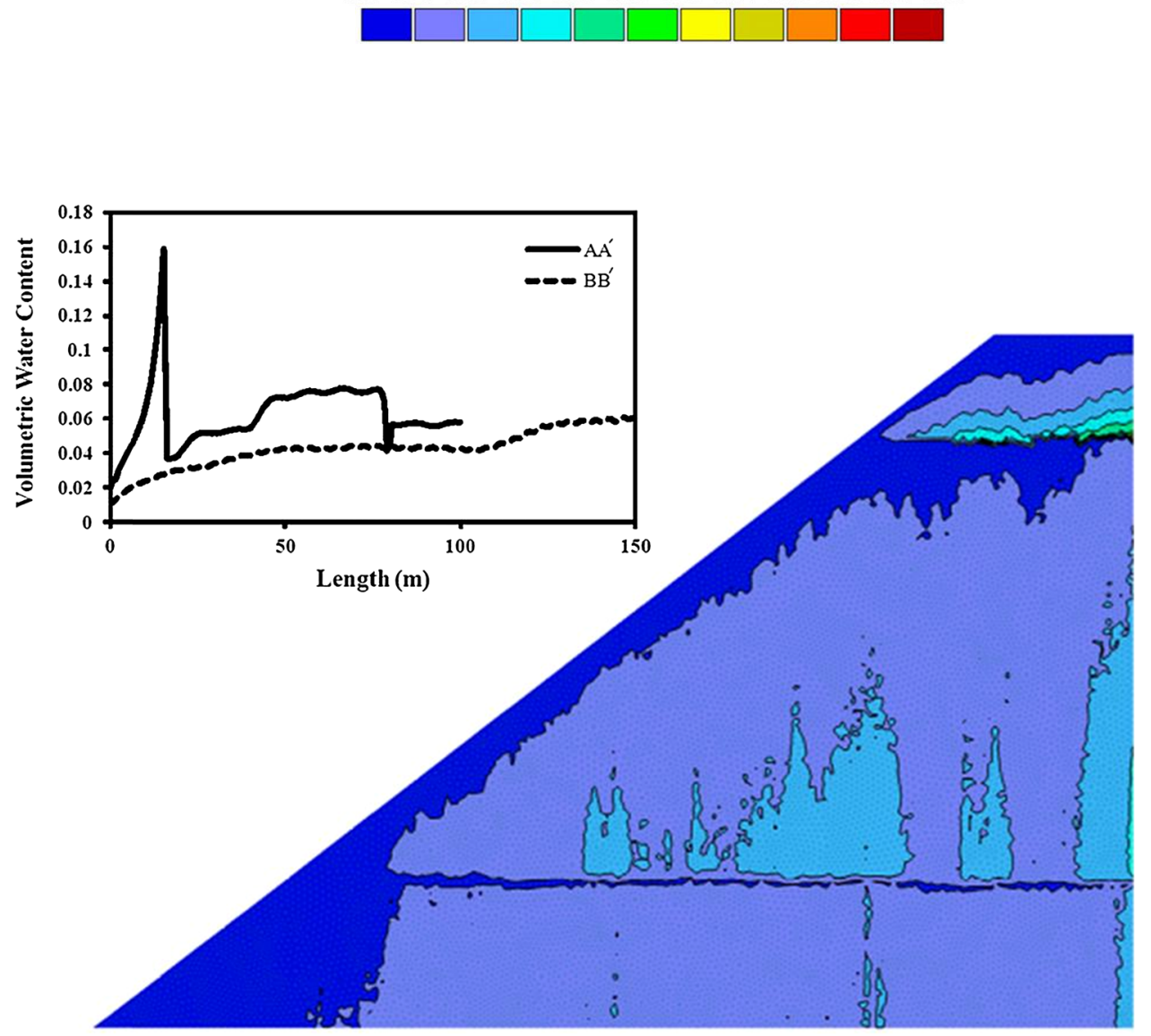

$\begin{array}{llllllllllll}0.009 & 0.047 & 0.085 & 0.122 & 0.160 & 0.198 & 0.236 & 0.273 & 0.311 & 0.349 & 0.387 & 0.424\end{array}$
Fig. 7 Water content contours of layered waste rock pile with vertical correlation (Simulation S3) and variations of water content in two observation lines $\mathrm{AA}^{\prime}$ and $\mathrm{BB}^{\prime}$ 
Fig. 8 Water content contours of layered waste rock pile with mixed correlation (Simulation S4) and variations of water content in two observation lines $\mathrm{AA}^{\prime}$ and $\mathrm{BB}^{\prime}$

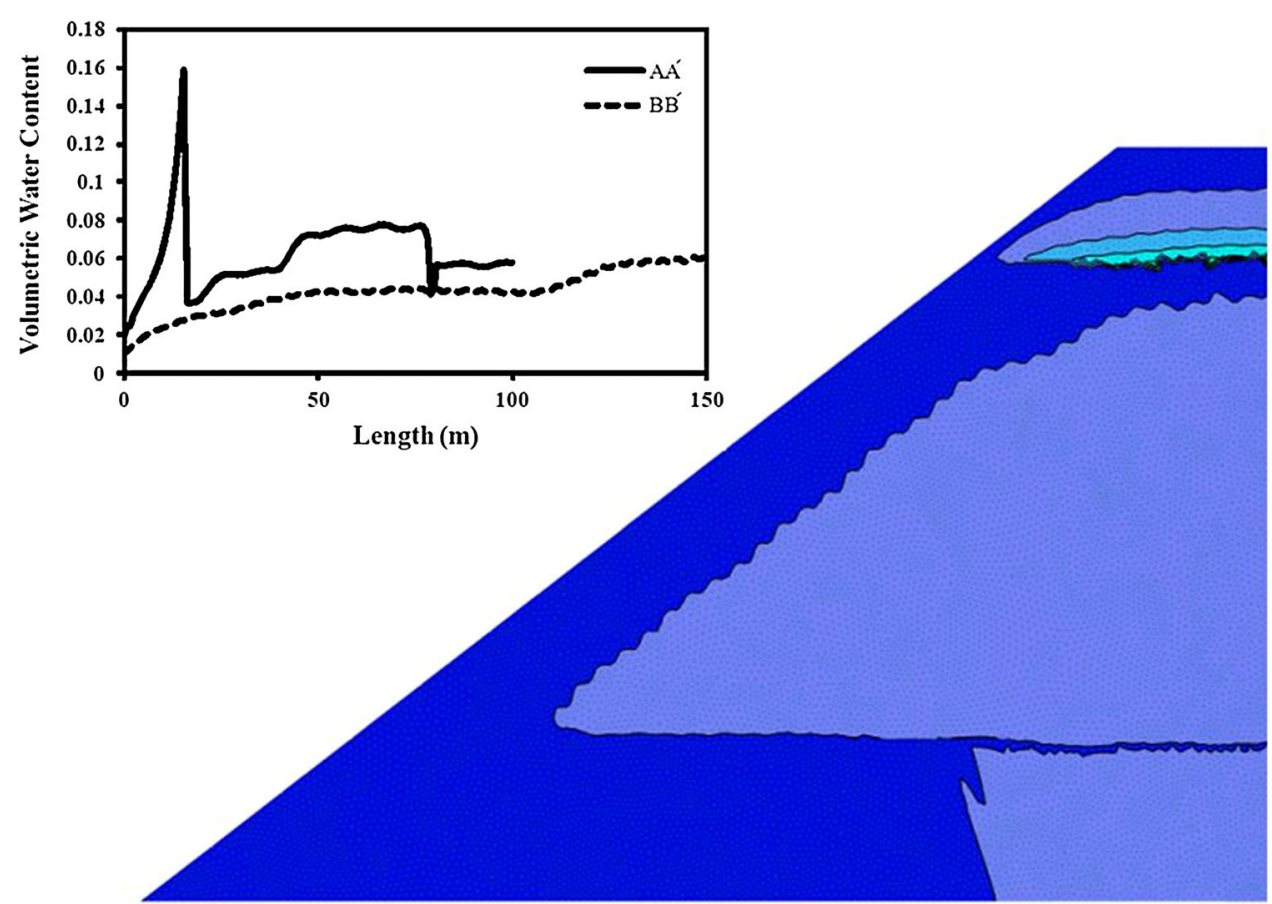

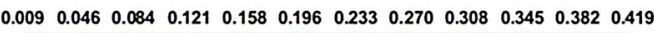

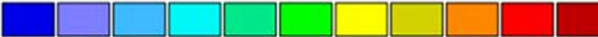

through the pile. So, only bottom fluxes of models influence on water balance of different cases. Table 4 presents the results of the waste rock water balance models. The percentages provided in the table summarize the water balance as a percent of the total precipitation.

The only scenario S2 (layered pile with horizontal correlation) shows negative water balance after 10 years of simulations. The negative value represents water lost from the pile. It is also found that the volumetric water content is so low in the $5 \mathrm{~m}$ from the surface and gradually increases toward depth. However, in none of these scenarios it exceeds $20 \%$ of waste rock saturation. Williams (2006) found that coarse-grained, durable, fresh waste rock only needs to reach about $20 \%$ saturation of its voids to be freedraining, while fine-grained, well-graded, weathered waste rock needs to reach about $60 \%$ saturation of its voids to be free-draining.

The degree of saturation is an important property affecting the various processes that contribute to acid rock drainage (Wels et al. 2003). Usually waste rock piles contain sulfidic minerals, which generate acidic drainage when they oxidize in the presence of oxygen and percolating water. The extremely few water content specially on the surface of the pile, have some effects on oxidation of sulfidic minerals by allowing inflow of oxygen and increasing movement of air by advection and convection in the pile (Aachib et al. 2004; Mbonimpa et al. 2003; Bussiere et al. 2003; Lefebvre et al. 2001). The oxygen flux
Table 4 Waste Rock pile water balance Model Summary

\begin{tabular}{llr}
\hline Scenario & \multicolumn{2}{c}{ Bottom flux } \\
& As a percent of precipitation $(\%)$ \\
\hline S1 & 28 & 18 \\
S2 & 59 & -15 \\
S3 & 42 & 3 \\
S4 & 19 & 28 \\
\hline
\end{tabular}

through the air is several orders of magnitude higher than a flux of oxygen into the waste pile from the oxygen dissolved in water infiltrating the surface of the pile (MEND 1993; Fredlund and Rahardjo 1993; Collin and Rasmuson 1988).

Generally, simulations resulted minor storage with respect to precipitation. Evaporation is responsible for $50 \%$ of water balance in waste rock, i.e.; $50 \%$ is infiltrated to waste rock, resulted different bottom flux and water storage. The high matric suction probably draws deeper moisture up to the surface of the pile where it can be evaporated. Also, the bottom flux among different modeled scenarios is high and is the main parameter determining storage of each scenario. The coarse waste rock materials cannot sufficiently hold the infiltrated water and allows easily draining downward. However, regarding amount of infiltrated water, the water lost from the base is not significant and therefore cannot pose a risk to the environment in future. 


\section{Conclusion}

The waste rock pile was modeled with layered water flow parameters and also with layered with stochastic properties in 4 scenarios. The water content distribution and waste balance were studied considering heterogeneity of materials. The modeling illustrated that the flux and storage values are different among different scenarios; however, the pile is unable to fully saturated and drain during simulated period. Although stochastic and non-stochastic properties shows different water flow pattern, but in general water flux from the bottom of the pile and evaporation is high and this decrease water storage capability of waste rock pile.

\section{References}

Aachib M, Mbonimpa M, Aubertin M (2004) Measurement and prediction of the oxygen diffusion coefficient in unsaturated media, with applications to soil covers. Water Air Soil Poll 156:163-193

Aubertin M, Ricard JF, Chapuis RP (1998) A predictive model for the water retention curve: application to tailings from hard-rock mines. Can Geotech J 35:55-69

Aubertin M, Mbonimpa M, Bussiere B, Chapuis RP (2003) A model to predict the water retention curve from basic geotechnical properties. Can Geotech J 40(6):1104-1122

Blowes D (1997) The environmental effects of mine wastes. In: Gubins AG (ed), Proceedings of exploration 97: Fourth Decennial International Conference on Mineral Exploration, pp 887-892

Bussiere B, Aubertin M, Chapuis R (2003) The behaviour of inclined covers used as oxygen barriers. Canad Geotech J 40(3):512-535

Collin M, Rasmuson A (1988) Gas diffusivity models for unsaturated porous media. Soil Sci Soc Am J 52:1559-1565

Dawood I, Aubertin M (2009) A numerical investigation of the influence of internal structure on the unsaturated flow in a large waste rock pile. In: 62nd Canadian Geotechnical Conference and 10th Joint CGS/IAH-CNC Groundwater Specialty Conference, Halifax, Nova Scotia

Dawood I, Aubertin M, Intissar R, Chouteau M (2011) A combined hydrogeological-geophysical approach to evaluate unsaturated flow in a large waste rock pile. Pan-Am CGS Geotechnical Conference, Toronto

Fala O, Aubertin M, Molson J, Bussière B, Wilson GW, Chapuis R, Martin V (2003) Numerical modelling of unsaturated flow in uniform and heterogeneous waste rock piles In: 6th International Conference on acid rock drainage (ICARD). Australasian Institute of Mining and Metallurgy, Cairns, QLD, Australia, Publ Series 3/2003, 12-18 July 2003, pp 895-902

Fala O, Molson J, Aubertin M, Bussière B (2005) Numerical modeling of flow and capillary barrier effects in unsaturated waste rock piles. Mine Water Environ 24:172-185

Fala O, Aubertin M, Bussière B, Chapuis R. Molson J (2008) Stochastic numerical simulations of long term unsaturated flow in waste rock piles. In: 61st Canadian Geotechnical Conference and 9th Joint CSG/IAH-CNC Groundwater Conference, Edmonton, Canada

Fala O, Molson J, Aubertin M, Dawood I, Bussière B, Chapuis RP (2013) A numerical modelling approach to assess long-term unsaturated flow and geochemical transport in a waste rock pile. Int J Min Reclam Env 27(1):38-55

Franklin M, Fernandes HM, van Genuchten MT (2008) Modeling the water flow in unsaturated waste rock pile: an important step in the overall closure planning of the first uranium mining site in Brazil. In: Merkel BJ, Hasche-Berger A (eds) Uranium, mining and hydrogeology. Springer Berlin Heidelberg, pp 177-186

Fredlund DG, Rahardjo H (1993) Soil mechanics for unsaturated soils. John Wiley, New York

Hopmans JW (1987) A comparison of various methods to scale soil hydraulic properties. J Hydrol 93:241-256

Hudson A, Dowell M, Kowalewski P (2012) Consideration of snow melt and physical aspect in simulating cover performance. 9th ICARD, Ottawa, Canada, 21-24 May 2012

Lahmira B, Lefebvre R, Aubertin M, Bussiere B (2007) Modeling the influence of hetrogeneity and anisotropy on physical process in ARD-producing waste rock piles. In: Proceedings of 60th Canadian Geotechnical Conference and the 8th Joint CGS/ IAH-CNC Groundwater Conference, Ottawa, 21-24 October 2007, pp 1486-1493

Lefebvre R, Hockley D, Smolensky J, Gelinas P (2001) Multiphase transfer processes in waste rock piles producing acid mine drainage 1: conceptual model and system characterization. J Contam Hydrol 52:137-164

Lottermoser B (2007) Mine wasters: characterization, treatment and environmental impacts, 2nd edn. Springer, Berlin

Mbonimpa M, Aubertin M, Aachib M, Bussiere B (2003) Diffusion and consumption of oxygen in unsaturated cover materials. Can Geotech J 40(5):916-932

McCord JT, Stephens DB, Wilson JL (1991) Hysteresis and statedependent anisotropy in modeling unsaturated hillslope hydrologic processes. Water Resour Res 27(7):1501-1518

MEND (Mine Environment Neutral Drainage Program) (1993) Field procedures manual gas transfer measurements waste rock, Heath Steele New Brunswick. Prepared by Nolan, Davis and Associates (N.B.) Limited, MEND report 1.22.1a, May

Miller EE, Miller RD (1956) Physical theory of capillary flow phenomena. J Appl Phys 27:324-332

Mualem Y (1976) A new model for predicting the hydraulic conductivity of unsaturated porous media. Water Resour Res 12(3):513-522

Nichol C (2002) Transient flow and transport in unsaturated heterogeneous media: field experiments in mine waste rock. $\mathrm{Ph}$.D. dissertation, University of British Columbia, Vancouver, Canada

Noel MM, Ritchie AIM (1999) Some physical properties of water transport in waste rock material. International Mine Water Association (IMWA) Proceedings, Sevilla, Spain

O'Kane Consultants Inc. (OKC) (2000) Demonstration of the application of unsaturated zone hydrology for heap leach optimization. Report No. 628-1 prepared for Industrial Research Assistance Program (IRAP), National Research Council Canada

Price WA (2009) Prediction manual for drainage chemistry from sulphidic geologic. Materials. MEND report 1.20.1. CANMETMining and Mineral Sciences Labratories. Smithers, British Columbia. V0J2N0

Simunek J, van Genuchten MT, Šejna M (2006) The HYDRUS software package for simulating two- and three-dimensional movement of water, heat, and multiple solutes in variablysaturated media, Technical Manual, Version 1.0, PC Progress, Prague, Czech Republic, p 241

Smith L, Beckie R (2003) Hydrologic and geochemical transport processes in mine waste rock. In: Jambor JL, Blowes DW, Ritchie AIM (eds) Environmental aspects of mine wastes, Ch 3, Short Course, vol 31. Mineralogical Association of Canada, pp 51-72 
Smith L, Lòpez DL, Beckie R, Morin K, Dawson R, Price W (1995) Hydrogeology of waste rock dumps, MEND report PA-1

Tetra Tech (2012) Infiltration, seepage, fate and transport modeling report-Revision 2, Rosemont Copper Project

Tuli A, Kosugi K, Hopmans JW (2001) Simultaneous scaling of soil water retention and unsaturated hydraulic conductivity functions assuming lognormal pore-size distribution. Adv Water Resour 24:677-688

Van Genuchten MT (1980) A closed-form equation for predicting the hydraulic conductivity of unsaturated soils. Soil Sci Soc Am J 44:892-898

Van Genuchten MT, Leij FJ, Yates SR, (1991) The RETC code for quantifying the hydraulic functions of unsaturated soils. U.S. Salinity Laboratory, U.S. Department of Agriculture, Agricultural Research Services, Riverside, California. Report EPA/600/ 2-91/065

Wagner K, Smith L, Beckie R (2006) Hydrogeochemical characterization of effluent from mine waste rock, Cluff Lake, Saskatchewan. Proceedings of the 7th International Conference on Acid Rock Drainage, St. Louis, MO, USA
Wels C, Lefebvre R, Robertson AM (2003) An overview of prediction and control of air flow in acid-generating waste rock dumps: In: Farrell T, Taylor G (eds). In: Proceedings of the 6th International Conference on acid rock drainage, Australasian Institute of Mining and Metallurgy, Cairns, Australia, Publ Series 3/2003, pp 639-650

Williams DJ (2006) Mine closure as a driver for waste rock dump construction. In: Proceedings of 1st International Seminar on Mine Closure, Perth, Australia, 13-15 Sept 2006, pp 697-706

Williams DJ (2011). Water management in the Australian minerals industry. In: Proceedings of the 34th IAHR World Congress, 33rd Hydrology and Water Resources Symposium and 10th Conference on Hydraulics in Water Engineering, Brisbane, QLD, Australia. 26 June-1 July 2011, pp 2201-2208

Williams DJ, Rohde TK (2008) Rainfall infiltration into and seepage from rock dumps - a review. In: Fourie A (ed) Rock dumps 2008: Australian Centre for Geomechanics, Perth, pp 79-89 